\title{
Indicadores de desarrollo sustentable. Aplicación de una metodología propuesta por la Organización de las Naciones Unidas*
}

C omo parte de los compromisos firmados por México durante la Conferencia de las Naciones Unidas sobre el medio ambiente y el desarrollo, se adoptó la denominada Agenda 21, que es un documento normativo con la perspectiva de alcanzar un desarrollo sustentable en los ámbitos social, económico y ecológico. En el documento se explica que la población, el consumo y la tecnología son las principales fuerzas determinantes del cambio ecológico y con mucha claridad se describe la necesidad de reducir las formas de consumo ineficientes y los desperdicios.

Entre otros rubros, se recomienda la utilización de un modelo de siete indicadores que incluye los consumos de plaguicidas y fertilizantes, los porcentajes de irrigación de la tierra y el uso de energía con fines agrarios, como evidencia de la presión ejercida sobre el medio ambiente; luego, se considera a la tierra arable como un indicador del estado del medio físico $y$, finalmente, a la educación agrícola como indicador de respuesta y vínculación entre los siete indicadores. Estos indicadores corresponden al capítulo 14 de la Agenda 21, en donde se describe cómo promover la agricultura sustentable y el desarrollo rural.
A su vez, los indicadores antes mencionados forman parte de un grupo de 132 indicadores y sus correspondientes series de tiempo que han sido ya estimados para el intervalo de 1980 a 1994 y en conjunto constituyen los insumos del modelo presion-estado-respuesta (PER). Además, apoyan la toma de decisiones en materia de mejoría ambiental.

\section{Descripción}

El reto para la agricultura es el incremento de la producción de alimentos en una forma sustentable. Una condición indeseable ha sido la incorporación permanente de químicos orgánicos que dañan a los ecosistemas; los plaguicidas pueden ser persistentes, móviles y tóxicos en la tierra, el agua y el aire. También, pueden tener un impacto negativo sobre los seres humanos y la vida animal a través de las cadenas alimenticias. Los plaguicidas tienden a acumularse en la tierra y sus residuos pueden alcanzar las aguas superficiales y los mantos acuíferos a través de la lixiviación.

El uso intensivo de los fertilizantes está relacionado con la eutroficación de los cuerpos de agua, la acidificación del suelo y la contaminación del agua con nitratos. Los efectos ambientales dependerán de las prácticas de abatimiento de la contaminación, los tipos de suelo, así como también de las condiciones meteorológicas que se presenten en las zonas de cultivo. En resumen, la utilización excesiva de los plaguicidas puede tener consecuencias muy severas, si los costos no se internalizan por parte de los agricultores y los sectores gubernamentales.

El porcentaje de irrigación en tierras arables nos muestra la extensión de tierra y los recursos de agua disponibles para ser usados de manera intensiva, con el propósito de obtener mejores rendimientos. La disponibilidad de tierras irrigadas está relacionada con los procesos de uso intensivo, pero también implica efectos negativos potenciales debidos al monocultivo, la selección de variedades agrícolas de alto rendimiento pero que restringen la diversidad genética, asi como la erosión, a compactación y la salinización del suelo. Finalmente, es necesario tener en cuenta el uso generalizado de aguas tratadas para el riego, que puede tener relación con la incidencia de enfermedades gastrointestinales y otros problemas de tipo tóxico.

El uso de energía para la agricultura es un indicador esencial. La

\footnotetext{
* La elaboración de esta sección estuvo a cargo de los licenciados Miguel Ángel Gallardo López y Sergio Vallejos Ortiz. Dirección General de Regulación Ambiental, Instituto Nacional de Ecología. Correo electrónico: ecoambi@ine.gob.mx.
} 
baja utilización de energía imposibilita al sector agrícola para mantener un nivel de productividad que le perimita satisfacer los requerimientos alimentarios de la población; en contraste, un consumo excesivo de energía significará un desperdicio y contribuye al calentamiento global y otros efectos adversos sobre el medio ambiente.

La capacidad de la agrícultura y de la tecnología para satisfacer la creciente demanda de alimentos es incierta. La población mundial está creciendo tan rápidamente que se pone en tela de juicio la capacidad de asegurar la suficiencia alimenticia de la sociedad. Dar otro uso a la tierra, como en el caso de los asentamientos humanos regulares e irregulares, es poner una presión adicional que limita la capacidad de respuesta ante las necesidades alimentarias.

Finalmente, la educación agrícola es muy importante desde el pun- to de vista de la sustentabilidad, ya que se refiere a la posibilidad de que los seres humanos trabajen con nuevas tecnologías, seguras, efectivas y de máxima eficencia.

\section{Conclusiones}

La publicación y análisis de estos siete indicadores nos ayudan a evaluar y comparar los avances nacionales en materia de agricultura sustentable y desarrollo rural, siguiendo la metodología que ha propuesto la ONU. Asimismo, la obtención de series de tiempo que abarcan un lapso de 15 años nos permitió cubrir las necesidades de información para los tres conceptos del modelo PER y mostrar que México se encuentra todavía en una etapa inadecuada con respecto a la utilización de plaguicidas y fertilizantes, y que muchos de los costos no son todavía internalizados, lo que trae como consecuencia que el gobierno utilice medidas restrictivas.
Por otro lado, el indicador de tierra arable per-cápita muestra una caída importante a partir de 1985.

Por último, la falta de educación agrícola indica la necesidad de fortalecer las políticas públicas y estimular a la iniciativa privada para alcanzar y mantener un óptimo nivel de productividad, incorporando y apropiándose de tecnologías de probados beneficios.

\section{Bibliografía}

CICLOPAFEST, SARH, SEDESOL, SECOFI. Catálogo oficial de plaguicidas. México, 1994.

INEGI. Anuario estadistico de los Estados Unidos Mexicanos, México, 1995.

United Nations. Indicators of sustainable development. Framework and methodologies. New York, 1996.

Promoción de la agricultura sustentable y el desarrollo rURAL

\begin{tabular}{|c|c|c|c|c|c|c|c|}
\hline \multirow{3}{*}{$\begin{array}{l}\text { Modelo } \\
\text { Años }\end{array}$} & \multicolumn{4}{|c|}{ Presión } & Estado & \multirow{2}{*}{\multicolumn{2}{|c|}{$\begin{array}{c}\text { Respuesta } \\
\text { Educación } \\
\text { agrícola }\end{array}$}} \\
\hline & $\begin{array}{l}\text { Uso de plaguicidas } \\
\text { agrícolas }\end{array}$ & $\begin{array}{c}\text { Uso de } \\
\text { fertilizantes }\end{array}$ & $\begin{array}{l}\text { Porcentaje de irrigación } \\
\text { en tierra arable }\end{array}$ & $\begin{array}{l}\text { Uso de energía } \\
\text { en la agricultura }\end{array}$ & $\begin{array}{l}\text { Tierra arable } \\
\text { per-cápita }\end{array}$ & & \\
\hline & $\begin{array}{c}\text { Consumo en toneladas } \\
\text { entre } 10 \mathrm{~km}^{2} \\
\text { de tierra agrícola }\end{array}$ & $\begin{array}{c}\text { Consumo en toneladas } \\
\text { entre } 10 \mathrm{~km}^{2} \\
\text { de tierra agrícola }\end{array}$ & $\begin{array}{l}\text { Porcentaje de tierra } \\
\text { irrigada del total } \\
\text { de tierra agrícola }\end{array}$ & $\begin{array}{c}\text { Consumo total } \\
\text { de energía } \\
\text { (joules } 10^{12} \text { ) }\end{array}$ & $\begin{array}{l}\text { Hectáreas } \\
\text { por } \\
\text { habitantes }\end{array}$ & $\begin{array}{l}\text { Porcentaje del gasto } \\
\text { total en educación } \\
\text { media }\end{array}$ & $\begin{array}{l}\text { Porcentaje } \\
\text { del } \\
\text { PIB }\end{array}$ \\
\hline 1980 & 1034 & 157.19 & 21.65 & 4.12 & 1.42 & 7.14 & 0.024 \\
\hline$\overline{1981}$ & 1956 & 171.14 & 21.83 & 3.52 & 1.39 & 8.54 & 0.034 \\
\hline 1982 & 1055 & 191.63 & 21.97 & 4.54 & 1.36 & 9.36 & 0.045 \\
\hline$\overline{1983}$ & 848 & 359.79 & 21.07 & 3.58 & 1.33 & 9.67 & 0.035 \\
\hline 1984 & 506 & 190.91 & 21.23 & 3.49 & 1.30 & 10.01 & 0.030 \\
\hline$\overline{1985}$ & 1217 & 204.89 & 22.98 & 3.12 & 1.28 & 12.57 & 0.046 \\
\hline 1986 & 861 & 197.31 & 22.50 & 3.73 & 1.26 & 15.94 & 0.071 \\
\hline 1987 & 1426 & 202.36 & 22.10 & 3.77 & 1.24 & 13.61 & 0.047 \\
\hline 1988 & 1017 & 188.34 & 22.61 & 4.50 & 1.22 & 12.61 & 0.046 \\
\hline 1989 & 1362 & 181.83 & 23.48 & 4.13 & 1.21 & 13.35 & 0.049 \\
\hline 1990 & 1227 & 167.42 & 24.35 & 3.33 & 1.19 & 11.68 & 0.038 \\
\hline 1991 & 1130 & 166.30 & 25.22 & 3.60 & 1.17 & 10.5 & 0.035 \\
\hline 1992 & 1174 & 104.30 & 26.52 & 3.23 & 1.15 & 9.16 & 0.032 \\
\hline$\overline{1993}$ & 1030 & n.d. & 26.52 & 3.45 & 1.14 & 9.87 & 0.037 \\
\hline 1994 & 2174 & n.d. & 26.52 & 3.19 & 1.12 & 11.3 & 0.042 \\
\hline
\end{tabular}

Fuente: Cálculos elaborados con información de los anuarios estadísticos de la Secretaría de Agricultura y Recursos Hidráulicos (SARH), varios años 